\title{
DOSSIÊ EDUCAÇÃO SEXUAL HOJE: REFLEXÕES E PERSPECTIVAS
}

\author{
EDUCACIÓN SEXUAL HOY: REFLEXIONES Y PERSPECTIVAS
}

SEX EDUCATION TODAY: REFLECTIONS AND PERSPECTIVES

\section{Ronielisson Loiola de Jesus TAVARES ${ }^{1}$ \\ Ana Cláudia Magnani Delle PIAGGE ${ }^{2}$}

O dossiê Educação Sexual hoje: reflexões e perspectivas, pretende discutir a atualidade e urgência das questões ligadas à sexualidade, a intersecção entre raça/etnia, classe e gênero e as relações sociais estabelecidas a partir da sexualidade de forma a ampliar a compreensão do tema, tendo em vista que a sexualidade é permeada por questões sociais e históricas.

Desse modo, o dossiê reúne um amplo espectro temático a respeito da Educação Sexual na atualidade, visando compartilhar novas possibilidades para pensar uma educação mais ampla e inclusiva para além da sua restrição a um caráter normativo medicista, buscando a construção de uma sociedade mais equânime e justa, na qual, as diferenças relativas às corporeidades, tais como as diferenças sexuais, de desejo, de gênero, de concepções de mundo, sejam respeitadas e valorizadas.

Entendemos a Educação Sexual, enquanto uma ciência interdisciplinar e uma prática, que vem conquistando, aos poucos, seu espaço e afirmando a sua importância. Entretanto, persistem ainda vários desafios a serem enfrentados, de modo a promover efetivamente a sua implementação. De forma a demonstrar a atualidade da temática pontuamos abaixo alguns momentos históricos que demonstram a trajetória desenvolvida no Brasil, explicitando alguns de seus avanços e retrocessos.

As primeiras discussões acadêmicas relacionadas à temática da sexualidade surgem no Brasil, no início do século XIX, movidas pela necessidade em promover intervenções relacionadas ao comportamento sexual dos indivíduos, de modo a controlar e prevenir a propagação das doenças de vênus, como eram conhecidas as infecções sexualmente

\footnotetext{
${ }^{1}$ Universidade Estadual Paulista (UNESP), Araraquara - SP - Brasil. Mestre em Educação Sexual no Programa de Pós-graduação em Educação Sexual. Bolsista CAPES. ORCID: https://orcid.org/0000-0003-1178-910X. Email: ronny.tavares@gmail.com

${ }^{2}$ Universidade Estadual Paulista (UNESP), Araraquara - SP - Brasil - SP. Mestranda no Programa de Pósgraduação em Educação Sexual. ORCID: https://orcid.org/0000-0001-6108-6395. E-mail: ana.magnani@unesp.br

RPGE- Revista on line de Política e Gestão Educacional, Araraquara, v. 24, n. esp. 3, p. 1679-1688, nov., 2020. e-ISSN: 1519-9029 DOI: https://doi.org/10.22633/rpge.v24iesp3.14587 
transmissíveis, e como forma de normatizar corpos e comportamentos, conformando-os a padrões europeus vigentes (RIBEIRO, 2004; 2009).

$\mathrm{Na}$ década de 1920 ocorrem as primeiras publicações desenvolvidas por médicos, educadores e religiosos, que inspirados pela perspectiva eugenista, higienista e na sexologia (área da medicina que estuda o sexo e a sexualidade numa perspectiva biomédica), versam pela educação dos indivíduos, estabelecendo normas que almejam a conformação das corporeidades às práticas sexuais consideradas "saudáveis” (RIBEIRO, 2009).

A família e, posteriormente, a escola foram convocadas a contribuir com o processo educativo, principalmente, do indivíduo em formação, no qual, os livros apresentavam distinções e especificidades em relação ao comportamento que deveria ser manifestado por homens e mulheres, atendendo a um modelo binário instituído. Essa educação deveria conformar as mulheres ao papel de esposa e mãe, subalternas ao homem (RIBEIRO, 1990; 2009).

As primeiras tentativas para inserir a Educação Sexual, enquanto disciplina escolar, ocorreram na década de 1930, no Rio de Janeiro, mas logo interrompidas, devido às acusações contra o professor responsável e pela influência da Igreja Católica. Anos mais tarde, em 1960, nos Estados de São Paulo, Rio de Janeiro e Minas Gerais ocorre uma nova tentativa, que buscava incorporá-la ao rol dos conteúdos escolares (ROSEMBERG, 1985; FIGUEIRÓ, 1998), novamente interrompida com a instauração da Ditadura Militar e sua postura moralista (RIBEIRO, 1990). Durante as décadas de 1960 e 1970, as discussões em defesa da necessidade de se implementar a Educação Sexual enquanto disciplina escolar ganham força na Câmara dos Deputados, ainda assim novamente rejeitada, mesmo contando com o apoio de congressistas e educadores (LEÃO, 2009).

Nos anos 80 ocorre o $1^{\circ}$ Congresso Nacional de Educação Sexual, fazendo ressurgir as discussões acerca de sua implementação, sendo negada pelo, então, Secretário de Educação José Bonifácio Coutinho Nogueira com a justificativa de este ser um assunto de responsabilidade da família (LEÃO, 2009). Essas discussões foram motivadas pelo aumento dos casos de gravidez na adolescência, fato que tornava urgente a instrução dos indivíduos em relação aos cuidados necessários para reduzir os percentuais de casos (BRASIL, 1997). Com uma perspectiva focada na prevenção, as ações eram voltadas a educar os indivíduos para a abstenção sexual, a instrução em relação aos métodos preventivos e contraceptivos e a descrição das principais enfermidades que poderiam ser contraídas através de práticas sexuais consideradas inadequadas. 
Em 1996, o Ministério da Educação incorporou a temática da Educação Sexual como tema transversal nos Parâmetros Curriculares Nacionais - PCNs. Nesses documentos, os conteúdos relativos à Educação Sexual deveriam ser discutidos por meio da apresentação de normas, condutas, valores ou silenciamentos em relação ao tema, utilizando-se mídia, livros e outras fontes de informação como ferramentas. Esse processo de aquisição de conhecimento a respeito da sexualidade deveria ocorrer de forma intencional, porém, seus resultados se mostram imprevisíveis (BRASIL, 1997).

O Ministério da Educação ao publicar o PCN, visava, por meio das ações desenvolvidas, a criação de estratégias e competências para que o aluno/a pudesse compreender as formas de prevenção da gravidez na adolescência e as ISTs, se apropriando da sexualidade de maneira positiva, reconhecendo e respeitando seus próprios sentimentos e dos outros (BRASIL, 1997).

O projeto Saúde e Prevenção nas Escolas (SPE), desenvolvido com a integração de ações entre agências da ONU, o Ministério da Educação e o Ministério da Saúde, foi um projeto que marcou os anos 2000, no qual o foco era a educação para a saúde, especificamente a prevenção às ISTs, sendo reformulado anos depois e renomeado como Programa Saúde na Escola (PSE), ocorrendo a ampliação das estratégias e a integração com os serviços de saúde, além da disponibilização de preservativos no ambiente escolar. Esse programa ainda se encontra vigente (UNESCO, 2014).

Entretanto, ainda há professores que desconhecem o Programa Saúde na Escola e as articulações entre a saúde e a educação ainda não foram bem estabelecidas, pois o trabalho não é realizado em equipe, pois, segundo Bringel et al. (2016), não há integração entre a Estratégia da Saúde da Família e a equipe que compõe a escola.

Em meio às diversas situações que até o momento persistem, seja pelo despreparo e insegurança dos docentes ou a concepção errônea por parte dos indivíduos que não compreendem em que consiste a prática educacional a respeito da sexualidade, reduzindo-a apenas a temática do sexo, notamos que a Educação Sexual na escola continua sendo tratada, por parte da sociedade, como um tema tabu, gerando desconfortos que se manifestam através dos silenciamentos e invisibilidades produzidas.

A partir de 2015 dá-se início, no legislativo brasileiro, a proposições relacionadas à prevenção contra uma tal "ideologia de gênero". De acordo com Reis e Eggbert (2017), o termo “ideologia de gênero" é uma falácia utilizada através do senso comum, da opinião própria e da desonestidade intelectual para a manutenção do status quo da sociedade a fim de promover a manutenção das desigualdades existentes, impedindo o avanço na garantia dos direitos das minorias. Mas o que seria, afinal, a Educação Sexual para ser tão temida e considerada por 
diversos indivíduos como sendo algo prejudicial, devendo o seu ensino ser restrito ao meio familiar?

A Educação Sexual é o termo cunhado para definir o processo educativo relacionado à sexualidade, desde o nascimento. Esta ocorrerá de maneira informal, através da família e dos pares e, de maneira formal, por meio de profissionais capacitados em um meio educacional (REIS; RIBEIRO, 2005; MAIA; RIBEIRO, 2011). Diversas áreas, tais como: Antropologia, História, Pedagogia, entre outras, contribuem na compreensão da sexualidade, demonstrando ser a sua constituição algo além de um processo meramente biológico (RIBEIRO, 2009). Como uma ferramenta educacional, possui objetivos, temáticas e metodologias aplicáveis por profissional capacitado, que atuará de modo a promover a discussão dos valores, normas, aspectos culturais e históricos que envolvem as práticas sexuais e sexualidade dos sujeitos (MAIA; RIBEIRO, 2011).

Tendo a consciência da emergência dessa temática, o dossiê Educação sexual hoje: reflexões e perspectivas, se propõe a reunir um amplo espectro temático a respeito da Educação Sexual na atualidade, visando compartilhar reflexões e novas possibilidades para pensar uma educação que seja, de fato, mais ampla e inclusiva.

De modo a demonstrar a amplitude e a relevância das temáticas relacionadas a Educação Sexual, essa coletânea reúne catorze artigos escritos por pesquisadores da Universidade Federal de Sergipe (UFS), da Universidade Estadual Paulista (UNESP), da Universidade Estadual do Paraná (UNESPAR), da Universidade Federal de Jataí (UFJ), da Universidade Federal de Mato Grosso do Sul (UFMS), da Universidade Estadual de Londrina (UEL), da Universidade Federal de Uberlândia (UFU), da Universidade Estadual do Ceará (UECE) e da Universidade Lusófona de Humanidades e Tecnologias (ULHT), Lisboa Portugal.

Iniciamos essa coletânea com a discussão proposta pelo artigo Saberes trans* em universidades nordestinas com autoria de: Helma de Melo Cardoso e Alfrancio Ferreira Dias, na qual, a partir de entrevistas realizadas com docentes transgênero, é proposta uma reflexão acerca dos desafios enfrentados por corpos trans em instituições de ensino superior em que, sua presença, torna-se motivo para questionamentos e estranhamentos. No transcorrer do trabalho é possível refletir como um espaço ocupado pela diversidade de corpos pode se tornar potente para a construção de uma sociedade mais equânime. Cardoso e Dias apontam que, mesmo com todos os obstáculos, esses/as professores/as desencadeiam novos padrões de aprendizagem, valorizam a afetividade e celebram a diferença, trabalhando num currículo produzido nas 
resistências diárias, na micropolítica, se desviando das diretrizes da macropolítica da educação que busca produzir subjetividades controladas.

No segundo artigo do dossiê, a temática da violência sexual infantil será abordada. Essa violência que assola corpos infantis, independente da etnia/raça ou da classe social, será exposta por este trabalho desenvolvido pelos pesquisadores: Artur Augusto Fernandes Leão Neto, Jéssica da Costa Jacinto e Ricardo Desidério, através de um levantamento bibliográfico. A curiosidade denegada: quando a infância negligenciada favorece o risco ao abuso sexual reflete sobre a eficácia que a implantação da disciplina de Educação Sexual pode promover para a redução dos casos de violência sexual contra crianças e adolescentes em todo país. Pois, para os autores, o abuso sexual infantil, encerra em si a ambivalência de ser tabu e urgente. Tabu, por ser proibido e cercado de segredos, discriminação, preconceito e urgente, pois se faz necessária a disponibilização de espaços adequados, éticos e cientificamente respaldados, dada a crescente e acentuada ocorrência deste modo de violação e violência contra a infância.

Dando continuidade às discussões acerca da relevância da Educação Sexual para prevenir situações de violência em diversos segmentos da sociedade, o artigo A Educação Sexual e a promoção da equidade de gênero no enfrentamento da violência doméstica contra mulheres, desenvolvido pelas pesquisadoras Mariana Passafaro Mársico Azadinho, Angelita de Lima Oliveira e Débora Raquel da Costa Milani, discorre sobre como a Educação Sexual pode contribuir para a mudança cultural em nossa sociedade, na qual, o machismo e o patriarcado ancoram a violência contra a mulher. As autoras concluem que a formação de um pensamento crítico pode colaborar com a construção de uma cultura igualitária, com a igualdade de gênero e enfrentamento de todas as formas de violência, discriminação e preconceito contra as mulheres.

No quarto artigo do dossiê, as pesquisadoras Lívia de Rezende Cardoso, Tássia Alexandre Teixeira Bertoldo, Linda Brasil de Azevedo Santos constroem um mapeamento com o objetivo de analisar as teses e dissertações em gênero, sexualidade e formação docente defendidas em programas de pós-graduação nas instituições de ensino superior das regiões Norte e Nordeste do Brasil, no intuito de desenvolver a pesquisa: Gênero e sexualidade na formação docente: um mapeamento das pesquisas entre Norte e Nordeste. Para este artigo, as autoras trouxeram 22 trabalhos que envolvem formação de professoras/es e, considerando o objetivo deste estudo, organizaram a discussão em duas unidades de sentido: a primeira voltada para os trabalhos que fazem análise da concepção de professoras/es em formação inicial e a segunda os trabalhos voltados para o currículo desta formação. Nessa perspectiva, foram observadas algumas contribuições, limites e possibilidades dessa produção acadêmica. 
Poderia o professor abordar a temática do racismo e dos papéis de gênero, atribuídos a homens e mulheres, por meio de um jogo? Esse é o tema presente no quinto artigo desse dossiê, que visa investigar as possibilidades oferecidas por um jogo de cartas como proposta educativa. Uma experiencia formativa na residência pedagógica: representação histórica feminina negra em um jogo de cartas, dos pesquisadores Lillian Rodrigues, Vagner Custódio e Lidiane Simão apresenta uma proposta educativa que visa contribuir com a luta antirracista e a redução da desigualdade de gênero. A metodologia utilizada pelos autores aborda a história de personagens históricas retratadas em um livro, por meio de um jogo de cartas com recurso de áudio e observações de campo, chegando-se ao resultado qualitativo de melhoria da autoestima, autoimagem e desempenho escolar dos alunos, concluindo que o preconceito, aliado aos papéis limitantes de gênero e a baixa autoestima podem ser fatores associados ao baixo desempenho escolar e a distúrbios de imagem corporal.

Os recursos midiáticos podem e devem ser utilizados como instrumento para promover a Educação Sexual em diferentes contextos. Os pesquisadores, Isabela Manchini, Jéssica da Costa Jacinto e Ricardo Desidério tem como objetivo analisar a série Sex Education da Netflix e sua relevância para o debate da Educação Sexual. Assim, em: A sexualidade silenciada no ambiente escolar e as contribuições da série Sex Education, os autores desenvolvem um estudo exploratório que nos permite refletir a escola como órgão inerente à sociedade, que se vê refletida em um paradigma marcado pelo reforço do senso comum atrelado às temáticas da sexualidade. Assim, denota-se que a escola deve ser responsável por disseminar uma Educação Sexual formal, baseada em estudos científicos acerca da sexualidade, mas esbarra em conceitos morais e deturpados de profissionais, impedindo, consequentemente, que haja uma discussão livre de dogmas e preconceitos e que, efetivamente, venha a sanar os questionamentos dos alunos da atual geração.

Os docentes Renan Martins Da Conceição Attab e Priscila da Silva Fernandes, autores do artigo A representatividade do salto alto, apontam que esse objeto do vestuário foi desenvolvido inicialmente para deixar o indivíduo mais alto, mais tarde assumindo a posição de peça essencial do vestuário feminino, além de item de fetiche, em nossa sociedade. Além da questão histórica, os autores se embasam na psicanálise para desenvolver seu argumento acerca do fetichismo envolvendo a trajetória do salto alto. Como metodologia, os autores realizaram uma pesquisa na qual se analisou fatos históricos, blogs e artigos científicos para o desenvolvimento teórico. Como resultado, obteve-se que o uso do salto alto no cotidiano pode ser muito prejudicial à coluna e às pernas da mulher e que o uso desse calçado é fruto de uma cultura machista, fundamentada no fetichismo do imaginário masculino. 
O debate em relação à violência de gênero na América Latina e Caribe é tema de suma importância, por esse motivo os pesquisadores Solange Aparecida de Souza Monteiro, Claudionor Renato da Silva e Paulo Rennes Marçal Ribeiro desenvolvem um estudo bibliográfico sobre a historicidade da violência de gênero desde a década de 1970 até os dias atuais. $\mathrm{O}$ artigo denominado: Por um histórico da violência de gênero na América Latina e Caribe: "possibilidades" para as pesquisas em educação sexual, contribui com reflexões sobre a violência de gênero enquanto um tema importante para os estudos da Educação Sexual. Este é o objetivo deste pequeno texto de natureza bibliográfica: indicar possibilidades de um estudo sobre uma historicidade da violência de gênero na macrorregião. São propostas duas possibilidades investigativas: um ponto de partida em documentos internacionais oficiais; outro ponto de partida são as pesquisas que falam da violência de gênero, desde os anos 1970 com teorias que tentaram explicar a violência de gênero, como o patriarcado, as epistemologias do sul, como exemplos.

No nono artigo desse dossiê, Maria Fernanda Celli de Oliveira e Luci Regina Muzzati, apontam que as questões relacionadas à sexualidade estão intrinsecamente ligadas ao desenvolvimento integral de qualquer indivíduo. As autoras consideram que ainda hoje é comum encontrar resistência em relação ao tema, sobretudo na escola, onde grande parte dos/as educadores/as sentem-se desconfortáveis ou não aptos para tratar tais assuntos. Desse modo, em Sexualidade infantil: a relação entre educação sexual e a identidade de gênero, as autoras pretendem levantar algumas reflexões acerca do possível entrelaçamento entre a Educação Sexual e a estruturação da identidade de gênero no que se refere a crianças em fase de educação infantil, tendo como embasamento teórico os pressupostos de Pierre Bourdieu.

Utilizando o ambiente acadêmico universitário como território para as suas investigações, as autoras do estudo Assédio moral e gênero na universidade pública: ressonâncias do produtivismo no trabalho docente, rastreiam indícios de assédio moral em uma universidade federal brasileira, buscando identificar situações ofensivas sofridas por homens e mulheres. O trabalho desenvolvido por Vanessa Catherina Neumann Figueiredo, Quezia Eloise França da Silva e Franciele Ariene Lopes Santana, utiliza o Questionário de Atos Negativos-Revisado e um formulário sociodemográfico e ocupacional em 35 professoras e 41 professores. O resultado da pesquisa apresenta evidências de assédio moral na amostra analisada. Para as pesquisadoras, a discrepância entre a percepção subjetiva de ter sido alvo de assédio (60\% mulheres e $47,8 \%$ homens) e a análise dos atos negativos demonstra a necessidade de acolhimento e de políticas organizacionais de enfrentamento da violência no trabalho. 
No décimo primeiro artigo, Marta Regina Furlan de Oliveira, Larissa Delgado Bueno da Silva e Jaqueline Delgado Paschoal, analisam criticamente as concepções de criança nos editoriais da moda, bem como avaliam se estes podem contribuir para o desenvolvimento precoce da "adultização" do consumidor infantil. Em seu artigo, Os lugares da infância nos editoriais de moda: uma análise sobre a adultização da criança na sociedade de consumo, as pesquisadoras refletem sobre a forma como, os discursos dos editoriais de moda infantil ditam padrões de beleza e de comportamentos semelhantes ao mundo adulto, principalmente em relação às roupas, acessórios, padrões estéticos e aos meios de consumo. Além disso, a Indústria da propaganda nem sempre considera as particularidades infantis ao vender seus produtos, contribuindo assim, para o processo de adultização das crianças. Por isso, para as autoras, é fundamental o papel da família e da escola como espaços de reflexões, combatendo os avanços da indústria cultural.

Fernanda Gomez, Paulo Rennes Marçal Ribeiro e Vagner Sérgio Custodio tratam, no décimo segundo artigo dessa coletânea, acerca das visões sobre a sexualidade de pessoas com comportamentos sexuais liberais na comunidade dos swingers e suas opiniões acerca da motivação no meio sexual liberal, mais especificamente verificar o ânimo ou desânimo decorrente da prática do swing. No artigo denominado: Um estudo sobre o swing a partir de visões fornecidas por integrantes de uma comunidade virtual de comportamento sexual liberal, os pesquisadores irão utilizar-se de um fórum de um website de comportamento sexual liberal. Foram ao todo 77 postagens classificadas conforme a ocorrência, analisadas e comentadas qualitativamente. Os autores buscam, com esse estudo, entender as regras para a troca de casais, a questão do prazer no swing, a concepção de sexo liberal e a realização sexual com essa prática a partir do que disseram, nas postagens, os sujeitos participantes do fórum.

Biscatinha: uma visão decolonial acerca da marginalidade imposta a meninas dentro do contexto da escola foi o artigo desenvolvido pelas pesquisadoras Ana Cláudia Magnani Delle Piagge e Tatiane Pereira de Souza para esse dossiê. A metodologia utilizada foi a pesquisa bibliográfica sustentada em autores e autoras decoloniais, dos estudos culturais, da diversidade etnicorracial e de gênero nas ciências humanas e sociais, bem como a observação in loco do cotidiano escolar. As pesquisadoras compreendem que o corpo da menina, dentro da escola, vem sendo educado, conformado, desumanizado para justificar um modelo impositivo de padrões de comportamento e pensamento normativo na sociedade, fato que colabora com o nosso entendimento acerca da urgência em promovermos mais discussões a respeito dessa temática. 
Finalizamos nosso dossiê com o artigo intitulado A prática de professores da educação infantil como ação preventiva da violência sexual de crianças desenvolvido por Márcia Cristiane Ferreira Mendes, Anaisa Alves de Moura e Maria da Paz Arruda Aragão. As pesquisadoras abordam a prática docente como forma de combate ao abuso e a exploração sexual de crianças, através das experiências obtidas no projeto de extensão e das ações pedagógicas ocorridas nos Centros de Educação Infantil públicas de Sobral - CE. Como resultado, apontam a importância da formação de professores para a prevenção ao abuso sexual de crianças e da relevância de planejar suas ações pedagógicas nesta perspectiva, além de proporcionar palestras para as famílias dos alunos como esclarecimento quanto à valorização familiar e a proteção e garantia de direito das crianças.

Finalizamos a apresentação desse dossiê esperando que vocês - leitores e leitoras possam encontrar nos textos aqui publicados, inspirações para novos diálogos e novas reflexões para a construção de uma Educação Sexual, com vista a respeitar a diversidade e a diferença. Que esse dossiê possa colaborar na construção de práticas mais equânimes.

\section{REFERÊNCIAS}

BRASIL. Parâmetros curriculares nacionais: pluralidade cultural, orientação sexual / Secretaria de Educação. Fundamental. - Brasília: MEC/SEF, 1997. 164p.

BRASIL. Ministério da Saúde Secretaria de Vigilância em Saúde. Departamento de Doenças de Condições Crônicas e Infecções Sexualmente Transmissíveis. Boletim epidemiológico HIV/Aids. Brasília: Ministério da Saúde, 2020a. Disponível em: http://www.aids.gov.br/pt-br/pub/2020/boletimepidemiologico-hivaids-2020. Acesso em: 15 dez. 2020.

BRASIL. Ministério da Saúde Secretaria de Vigilância em Saúde. Departamento de Doenças de Condições Crônicas e Infecções Sexualmente Transmissíveis. Boletim epidemiológico Sífilis.

Brasília: Ministério da Saúde, 2020b. Disponível em: http://www.aids.gov.br/pt-br/pub/2020/boletimsifilis-

2020\#: :text=A\%20presente $\% 20$ edi $\%$ C3\%A7\%C3\%A3o\%20do\%20Boletim,de $\% 20$ dados $\% 20 \mathrm{~b} \% \mathrm{C} 3$ $\% \mathrm{~A} 1$ sicos\%2C\%20indicadores\%20e. Acesso em: 15 dez. 2020.

BRINGEL, N. M. M. et al. Posturas e estratégias sobre sexualidade a partir do programa saúde na escola: discursos de professores. Revista de Enfermagem da UFSM, v. 6, n. 4, p. 494-506, 2016. Disponível em: https://periodicos.ufsm.br/reufsm/article/view/21538/pdf. Acesso em: 20 dez. 2020.

LEÃO, A. M. C. Estudo analítico-descritivo do curso de pedagogia da UNESP-Araraquara quanto a inserção das temáticas de sexualidade e orientação sexual na formação de seus alunos. 2009. 343 f. Tese (doutorado) - Universidade Estadual Paulista Júlio de Mesquita Filho, Faculdade de Ciências e Letras de Araraquara, 2009. Disponível em: http://hdl.handle.net/11449/101587. Acesso em: 20 dez. 2020

MAIA, A. C. B.; RIBEIRO, P. R. M. Educação sexual: princípios para ação. DOXA, v. 15, n. 1, p. 7584, 2011. 
REIS, T.; EGGERT, E. Ideologia de gênero: uma falácia construída sobre os planos de educação brasileiros. Educ. Soc., Campinas, v. 38, n. 138, p. 9-26 jan. 2017. Disponível em:

http://www.scielo.br/scielo.php?script=sci_arttext\&pid=S0101-

73302017000100009\&lng=en\&nrm=iso. Acesso em: 14 dez. 2020.

REIS, G. V.; RIBEIRO, P. R. M. Sexualidade e educação escolar: algumas reflexões sobre orientação sexual na escola. In: MAIA, A.C.B.; MAIA, A.F. (Org.). Sexualidade e infância. Bauru: FCL/CECEMCA; Brasília: MEC/SEF, 2005. p. 35-44.

RIBEIRO, P. R. M. Educação sexual além da informação. São Paulo: EPU, 1990.

RIBEIRO, P. R. M. Os momentos históricos da educação sexual no Brasil. In P. R. M. Ribeiro (Org.). Sexualidade e educação: aproximações necessárias. São Paulo: Arte \& Ciência, 2004. p. 15-25.

RIBEIRO, P. R. M. A institucionalização dos saberes acerca da sexualidade humana e da educação sexual no Brasil. Educação sexual: múltiplos temas, compromissos comuns. Londrina: UEL, p. 129-140, 2009. Disponível em: http://www.cepac.org.br/blog/wp-

content/uploads/2011/07/Educacao_Sexual_Multiplos_Temas.pdf. Acesso em: 15 abr. 2019.

SCALA, J. Ideologia de Gênero: o neototalitarismo e a morte da família. Zenit. 31 jan. 2012.

Disponível em: https://pt.zenit.org/articles/ideologia-de-genero-neototalitarismo-e-a-morte-da-familia/. Acesso em: 20 set. 2020.

ROSEMBERG, F. Educação sexual na escola. Cad. Pesq., São Paulo, n. 53, p.11 - 19, maio 1985. Disponível em: http://publicacoes.fcc.org.br/ojs/index.php/cp/article/view/1372/1373. Acesso em 18 ago. 2020.

UNESCO. Orientações técnicas de educação em sexualidade para o cenário brasileiro: tópicos e objetivos de aprendizagem. Brasília: UNESCO, 2014. Disponível em:

https://unesdoc.unesco.org/ark:/48223/pf0000227762. Acesso em: 20 nov. 2020.

UNESCO. Orientações técnicas de educação em sexualidade: uma abordagem baseada em evidências ( $2^{\mathrm{a}}$ ed. rev.). Brasília: UNESCO, 2019. Disponível em:

https://unesdoc.unesco.org/ark:/48223/pf0000369308?posInSet=1\&amp;queryId=54496777-a2a3- . Acesso em: 24 nov. 2020.

\section{Como referenciar este artigo}

TAVARES, R. L. de J.; PIAGGE, A. C. M. Dossiê educação sexual hoje: reflexões e perspectivas. Revista on line de Política e Gestão Educacional, Araraquara, v. 24, n. esp. 3, p. 1689-1712, dez. $2020 . \quad$ e-ISSN:1519-9029. DOI: https://doi.org/10.22633/rpge.v24iesp3.14587

Submetido em: 10/08/2020

Revisões requeridas: $20 / 10 / 2020$

Aprovado em: 05/11/2020

Publicado em: 30/11/2020 